\title{
Physical and mechanical properties of particleboards manufactured using charcoal as additives
}

\author{
Grzegorz Kowaluk, Mateusz \\ Zajac, Ewelina Czubak, \\ Radoslaw Auriga
}

\begin{abstract}
The objective of this work was to evaluate selected physical and mechanical properties of experimental particleboards manufactured from pine and spruce with charcoal particles in their core layer. For all the manufactured boards the average density was $750 \mathrm{~kg} \mathrm{~m}^{-3}$, while the mass share of charcoal in the core layer was changed $(0 \%, 10 \%$ and $50 \%)$. The manufactured panels were tested with respect to their mechanical and physical properties, including formaldehyde emission. The results indicated that the share of charcoal significantly influenced mechanical properties, swelling, and water relations of the boards. In addition, a test on formaldehyde emission from panels were carried out, which revealed that the charcoal share has a considerable impact on the amount of formaldehyde released by the manufactured boards. The $50 \%$ content of charcoal caused about $80 \%$ reduction of formaldehyde emission.
\end{abstract}

\section{Keywords: Charcoal, Particleboard, Filler, Bending, Formaldehyde, Emission} to UF resin allow to obtain the MUF resin, which captures the formaldehyde and decrease its emission (Luo et al. 2015). However, melamine addition significantly increases the production cost of panels, thus its use is often limited.

Recently, Zhang et al. (2011) reported on the reduction of formaldehyde emission from wood products without decreasing the mechanical properties of the UF resin, through the use of nanocrystalline cellullose (NCC) modified by the addiction of APTES (3-Aminopropyl triethoxysilane) and MPS (3-Methacryloxy propyltrimethoxysilane). UF resin supplemented with $1.5 \%$ APTES NCC has proven to reduce formaldehyde emission by $53.2 \%$ and increase the bonding strength by $23.6 \%$, while the addiction of MPS yielded slightly lower performances (Zhang et al. 2011). Moreover, the effect of ammonia and sodium sulfite on formaldehyde emissions was also investigated by Wang et al. (2012), who used lowmolecular-weight phenol-formaldehyde oligomers (PFO) to improve water resistance of a whey protein-based adhesive and decrease formaldehyde emissions from ply- els. Alternatively, the addition of melamine

Faculty of Wood Technology, Warsaw University of Life Sciences, Nowoursynowska Str. 159, 02-776 Warsaw (Poland)

@ Grzegorz Kowaluk (grzegorz_kowaluk@sggw.pl)

Received: Dec 22, 2015 - Accepted: Feb 29, 2016

Citation: Kowaluk G, Zajac M, Czubak E, Auriga R (2016). Physical and mechanical properties of particleboards manufactured using charcoal as additives. iForest 10: 70-74. - doi: 10.3832/ifor1963-009 [online 2016-06-29]

Communicated by: Giacomo Goli woods assembled with PFO-modified adhesive, with non-significant effects on its binding properties.

According to Ding et al. (2013), surface finishing of wood-based materials also affects their formaldehyde emission. For example, higher formaldehyde emissions have been reported for surface-sealed plywood as compared with plywood not subjected to sealing treatment (Ding et al. 2013). Contrastingly, edge sealing of nineply poplar plywood with UF resin decreased formaldehyde emissions by $74.4 \%$. Further, by comparing different coating procedures such as low pressure laminate (LPL), polyvinyl chloride (PVC), coating paper, direct coating and veneer overlayl UV lacquer, Park et al. (2013) showed that the latter method has the lowest formaldehyde emission. Chen et al. (2014) investigated the relation between assembly time of plywood and its properties, and showed that the plywood pre-pressed for 0 to $8 \mathrm{~h}$ before hot pressing had the lowest formaldehyde emission.

A further method aimed at decreasing formaldehyde emission from UF resin is the application of wood-derived bio-oil in the production of three-layered plywood ( $\mathrm{Li}$ et al. 2014), which also does not decrease its bonding strength. Other studies showed that formaldehyde emission can be reduced by over $42 \%$ by decreasing the melamine allocation proportion (in the alkaline hydroxymethylation step $-M_{1}$ and/or alkaline post amino addition step $-M_{2}$ ) in three-layer plywood bonded by MUF resin (Luo et al. 2015). According to these authors, cheap sepiolite can replace wheat flour as glue mass filler (80\%) with MUF resin in plywood production, with an observed reduction of emissions by $7.8 \%$ Kumar et al. (2013) studied the effect of the 
addition of small amounts of activated carbon on formaldehyde emissions from composite materials, showing an improvement in terms of modulus of rupture and internal bonds, as well as a significant decrease of emissions. Akgül et al. (2013) investigated the influence of burned wood as a component of panels bonded by melamine-ureaformaldehyde (MDF), and made of various mixtures of burned and unburned wood of pine, beech and oak. All the panels met the European standards in terms of mechanical properties of the MDF, though the surface roughness increased and the dimensional stability decreased with the addition of burned wood; formaldehyde emission was not investigated.

The above mentioned results suggest the existence of a correlation between the presence of thermally processed wood, including charcoal, in selected wood-based composites structure, and formaldehyde emission from these composites. The goal of this study was to evaluate selected physical and mechanical properties of experimental particleboards manufactured from pine and spruce with different content of charcoal particles in the core layer.

\section{Material and methods}

\section{Panels}

Three layer particleboards with dimensions $320 \times 320 \times 12 \mathrm{~mm}^{3}$ and average assumed density of $750 \mathrm{~kg} \mathrm{~m}^{-3}$ were produced from industrial particles for particleboards production. The moisture content of the particles was about $5 \%$. The raw material for particles was $95 \%$ chips of softwood species such as Scots pine (Pinus sylvestris L.) and Norway spruce (Picea abies Karst.). The face-to-core layers ratio (by weight) was 32:68. Three different panel variants were produced: (0) the reference panel, with no charcoal particles in the structure; (10) with $10 \%$ of the core layer weight made by charcoal particles; and (50) with $50 \%$ of the core layer weight made by charcoal particles. For each variant, 4 panels were produced. The origin of the commercially available charcoal was beech (Fagus sylvatica L.) and hornbeam (Carpinus betulus L.) wood, with a moisture content of $5 \%$. The commercial charcoal was ground to particles by a hammer mill, and then sieved with mesh to obtain particles of 1 to $4 \mathrm{~mm}$. As bonding agent, ureaformaldehyde (UF) industrial resin, typically used for particleboard production, was used. The hardener was a water solution of ammonium chloride $\left(\mathrm{NH}_{4} \mathrm{Cl}\right)$, in proportion 8:100 (hardener solution to resin) by weight, to achieve the curing time of glue mass to about $86 \mathrm{~s}$ at $100{ }^{\circ} \mathrm{C}$. The resination of face and core layers was $12 \%$. No paraffin vax was used. A glue mass was pneumatically spread onto wood (and charcoal) particles mixed in a drum resinator. After manual forming, the mats were pressed in a hot press under the following conditions: temperature $180{ }^{\circ} \mathrm{C}$; specific pressing pressure $2.5 \mathrm{MPa}$; pressing time factor $15 \mathrm{~s} / 1 \mathrm{~mm}$ of the panel thickness. Panels were then conditioned in $20{ }^{\circ} \mathrm{C}$ and $65 \%$ of relative humidity (RH) to weight stabilization, reaching an equilibrium moisture content (EMC) of about $8 \%$ before testing.

\section{Mechanical properties}

At least 10 samples of each panel variant were used in testing their mechanical and physical properties. As for density profile measurements, 3 samples of each variant were used, and 2 samples of each variant for formaldehyde emission. Mechanical tests were carried out by using a computer-controlled INSTRON universal testing machine. The following parameters were assessed:

- Modulus of Rupture (MOR) and Modulus of Elasticity (MOE) in static bending, according to EN310 (1994),

- Internal bond (IB), according to EN319 (1993),

- Screw withdrawal resistance (SWR), according to EN320 (2011).

\section{Physical parameters}

Thickness swelling (TS) after 2 and 24 h of soaking in water was measured according to EN317 (1993) using 10 samples of each panel type. Water absorption (WA) was investigated while measuring TS, and calculated as follows (eqn. 1):

$$
W A=\frac{m_{2}-m_{1}}{m_{1}} \cdot 100
$$

where $W A$ is the water absorption (\%), $m_{1}$ is

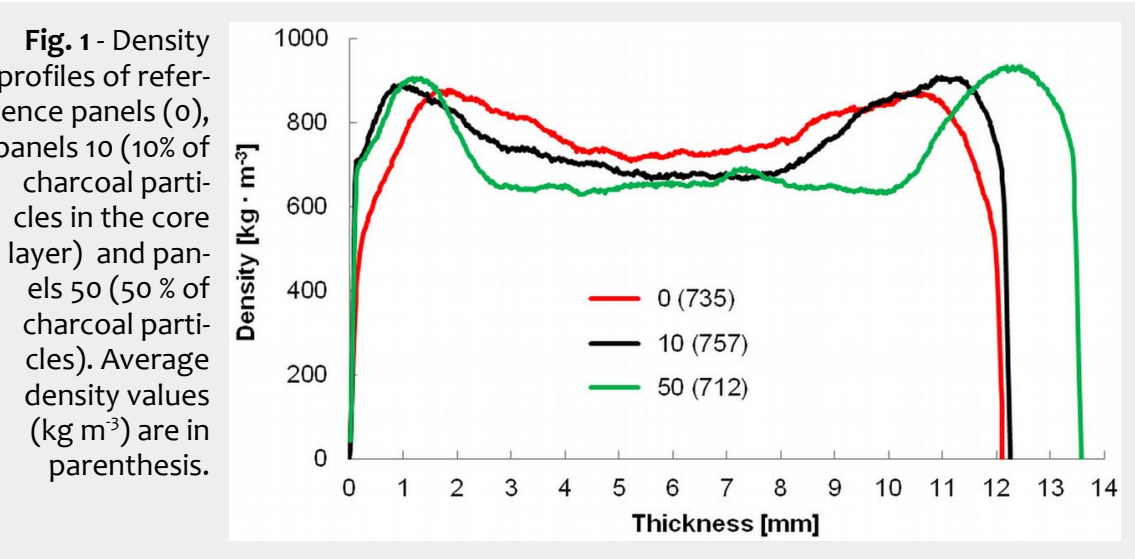

the sample weight before soaking (in g), and $m_{2}$ is the sample weight after soaking (in $\mathrm{g}$ ).

Formaldehyde emission (FE) was measured according to EN717-2 (1999) standard in 2 samples per each panel type. Density profile was measured using a GreCon Da- $X^{\circledR}$ (x-ray) analyser (Fagus-GreCon Gmbh, Alfeld-Hannover, Germany), with $0.02 \mathrm{~mm}$ panel thickness sampling step on 3 samples for each panel type.

\section{Statistical analysis}

The analysis of variance (ANOVA) was carried out to test for differences among different panel types (panels 0 , panels 10 , panels 50) in mean values of all the measured variables, except formaldehyde emission and density profile. Linear regression $(\alpha=0.05)$ was applied to investigate the relationship between formaldehyde emission and the charcoal particle content of the tested panels.

\section{Results and discussion}

\section{Density profile}

The density gradient between face and core layers increased with increasing the charcoal content in the core layer (Fig. 1), thus the transition between face and core layers was more marked. Their difference in density was about $146 \mathrm{~kg} \mathrm{~m}^{-3}$ for reference panels (0), $230 \mathrm{~kg} \mathrm{~m}^{-3}$ for panels 10 and $258 \mathrm{~kg} \mathrm{~m}^{-3}$ for panels 50. Mean density of the core layer slightly decreases with increasing charcoal particles share. A slightly lowered average density (712 vs. $750 \mathrm{~kg}$ $\mathrm{m}^{-3}$ ) was recorded for panels 50 as a consequence of their increased thickness (13.58 $\mathrm{mm}$ ), likely due to the limited densification of charcoal particles. The plasticization process of charcoal under elevated temperature and pressure can be unequal and not as intensive and stable as for wood particles. However, no significant (lower) density regions in the core layer of panels with charcoal were detected on the plot, indicating the absence of undensified particles of charcoal. Indeed, this kind of material has been reported to show density values as low as $300 \mathrm{~kg} \mathrm{~m}^{-3}$ or even less (Shi et al. 2007).

\section{Mechanical properties}

The modulus of rupture (MOR) of tested panels significantly decreases with increasing the share of charcoal particles in the core layer (Fig. 2). The MOR for panels 10 (10\% of charcoal particles applied in the core layer) decreased by about $19 \%$ as compared to panels o (reference panels), while for panels 50 (50\% of charcoal particles) such reduction was about $46 \%$. All the differences in average MOR values between panels types were statistically significant $(p<0.05)$.

The decrease of MOR observed for panels 10 and panels 50 is likely caused by the brittleness of charcoal particles embedded in their core layer. In fact, the bending 
strength of flat materials, such as particleboards, is known to depend on the tension/compression strength of face layers, as well as on the shear strength of the core zone. It was observed that in the panels 50 (highest content of charcoal) the damage during bending occurs due to shear forces in the core layer, while in the panels o the damage occurred in the face layers. During the pressing of layers, charcoal particles may provoke cracks at different scale in the panels, due to their lower thermoplasticity compared to wood particles. This could still determine a high compression resistance of the panels, but a lowered resistance to shear.

Regarding the modulus of elasticity (MOE), significant differences were found between panels 0 and panels 50, as well as between panels 10 and panels 50 . In this case, the lower bending strength of charcoal particles is counterbalanced by their rigidity (strongly connected to brittleness), as well as by the higher densification of face layers. In particular, no MOE reduction was detected for panels 10, probably because of the close-to-optimal content ratio of stiff charcoal particles densified closer to the surface layers, which results in a higher load and comparable low deflection. However, according to EN312 (2010), only panels o (reference) and panels 10 meet the requirements of minimal MOR values for $\mathrm{P} 2$ type panels (applied to materials for interiors and furniture), while MOE minimal requirements were met by all the tested panels.

\section{Internal bond strength}

The differences in density profile described above might potentially affect the internal bond (IB) of the tested panels. However, we found no significant decrease of IB strength by increasing from o to $10 \%$ the charcoal particles content in the core layer (Fig. 3). In contrast, IB values of panels 50 ( $50 \%$ of charcoal particles) were significantly lower compared with the other two panel types.

Breaks in the surface layer $(1-2 \mathrm{~mm}$ in depth) were observed in few samples during this test, especially in panels 0 . This may indicate that the press closing speed was too slow, so the surface layers dried out before full pressure was applied. In fact, the surface density of reference panels is lower compared to the core layer. Contrastingly, in panels 50 (where the densification of face layers was higher) the cracks occurred in the core layer, which had the lowest density and a higher charcoal content. It is worth noting that the IB standard deviation decreased with increasing the charcoal content of the panels (Fig. 3 ), which is also due to the higher densification of face layers, thus moving the fracture zone closer to the middle of panel thickness. None of the tested panels met the requirements of minimal IB strength for panel type $\mathrm{P} 2$, according to EN312 (2010) standard.
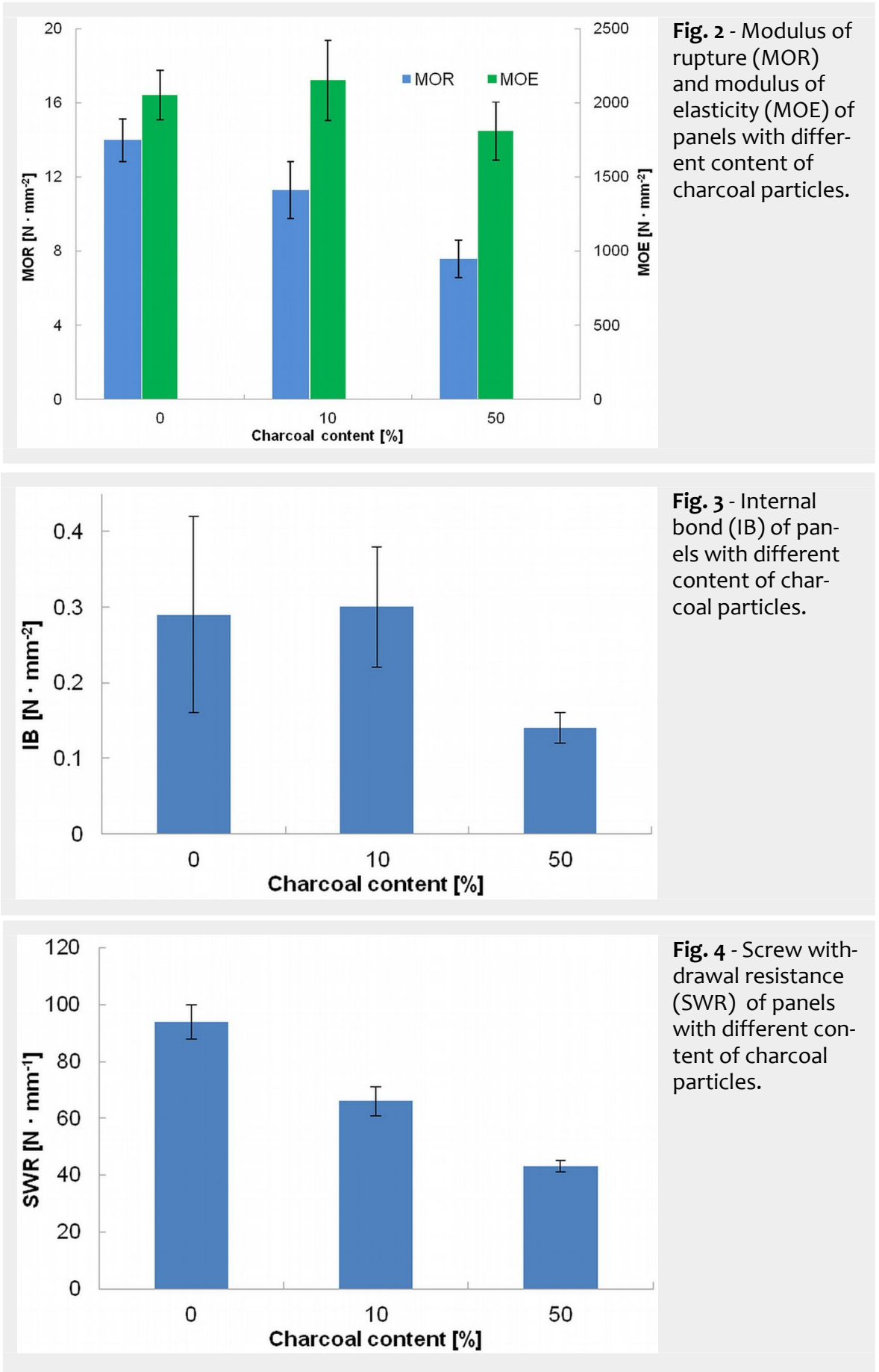

\section{Screw withdrawal resistance}

The screw withdrawal resistance (SRW) significantly decreased with increasing charcoal particles content in the core layer of particleboards. As compared with reference panels (0), SWR decreased by about $30 \%$ for panels 10 and over $54 \%$ for panels 50 (Fig. 4), with statistically significant differences between all the means of the three panel types. This suggests that the resistance of the rigid charcoal particles incorporated into the particleboard is not sufficient to face the screwing load, that tear and split the charcoal particles like a wedge. In this case, with the increased amount of charcoal particles in the core layer, SWR mostly depends on the strength of the thin surface layers, which represent
Fig. 3 - Internal bond (IB) of panels with different content of charcoal particles. only $32 \%$ by weight of the composite panels.

\section{Thickness swelling}

After soaking in water for 2 hours, thickness swelling (TS) was observed to increase with increasing the charcoal particle content in the core layer, with significant differences between panels 0 and panels 50 (Fig. 5). It is likely that panels containing charcoal particles could be penetrated by water more easily than reference panels due to their structure. However, the initial soaking time ( $2 \mathrm{~h}$ ) was long enough to fully soak the face layers.

After $24 \mathrm{~h}$ of soaking, the only significant difference in TS was observed between panels 0 and panels 10. Longer soaking 
Fig. 5 - Thickness swelling (TS) of panels with different content of charcoal particles.

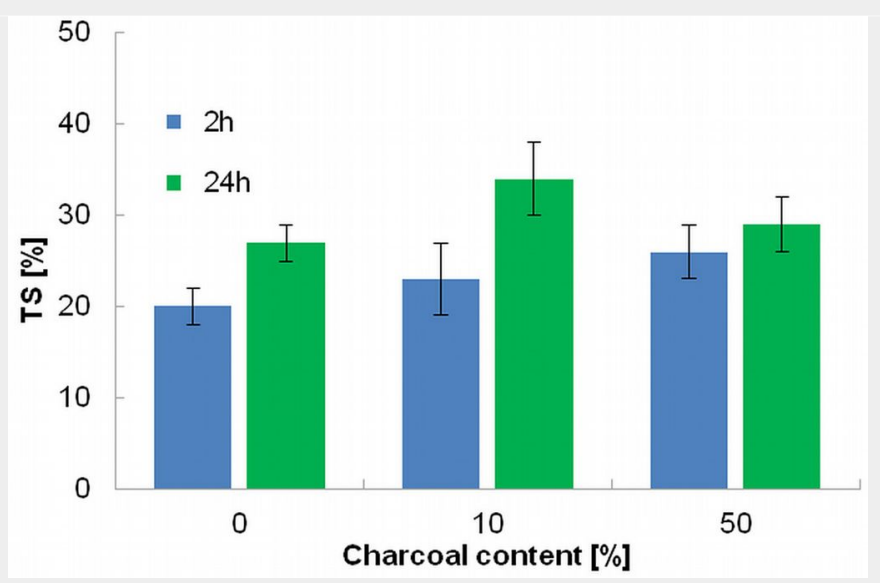

Fig. 6 - Water absorption (WA) of of panels with different content of charcoal particles.

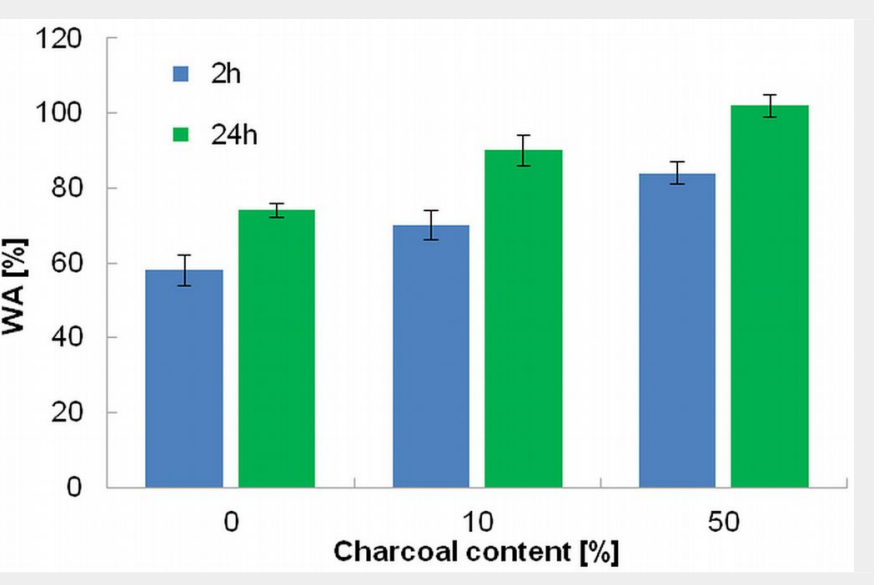

Fig. 7 - Results of the linear regression between the charcoal content of the tested panels and their formaldehyde emission.

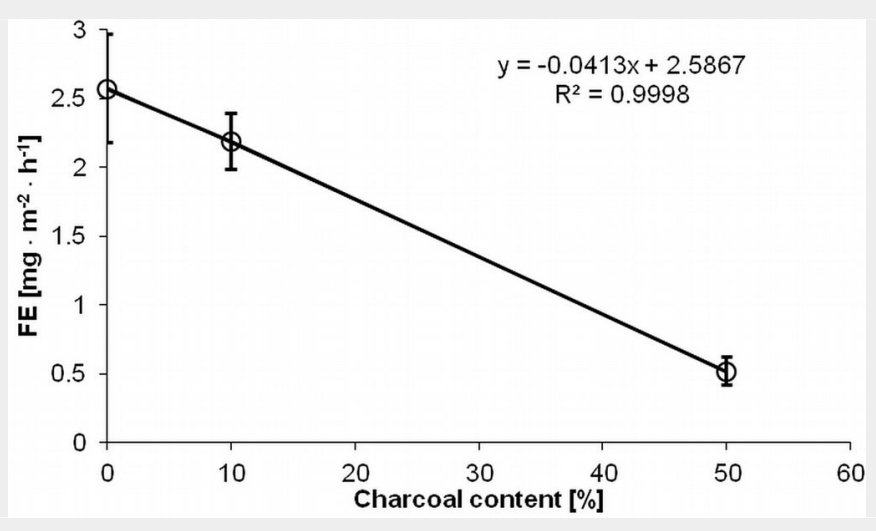

time did not cause significant thickness change of panels 50 . After $24 \mathrm{~h}$ of soaking, the highest thickness swelling (34\%) was reached by panels with $10 \%$ of charcoal. The reason of the high swelling in thickness of panels 10 can be their higher density, compare to the other tested panels. Since the thickness of panels 50 was over $13.5 \mathrm{~mm}$ (thus having a lower density), these panels could not reach high thickness swelling. It is worth to mention that according to EN312 (2010) standard, the maximum thickness swelling after $24 \mathrm{~h}$ of soaking in water for panels type $\mathrm{P}_{3}$, nonload bearing, to be used in humid conditions, is $17 \%$. None of the tested panels matched the above standard requirement.

\section{Water absorption}

Water absorption increased as the char- coal content of the core layer of panels increases (Fig. 6). After $2 \mathrm{~h}$ of soaking, the difference in water absorption between panels 0 and panels 10 was about $21 \%$, and raised to about $45 \%$ by comparing panels 0 and panels 50. After $24 \mathrm{~h}$ of soaking, water absorption differed by about $22 \%$ between panel 0 and panels 10, by about 38\% between panels 50 and reference panels. This result indicates that the intensity of water absorption decreases with the increase of soaking time and charcoal content of the panels. This can be explained by differences in the physical structure between wood and charcoal particles. Indeed, the latter showed a greater specific surface, thus they can absorb water more easily and maximal water uptake can be reached in a shorter period of soaking. Contrastingly, wood particles, which are compressed in the panels, need a longer time to reach the maximum water absorption level because of their lower specific area.

\section{Formaldehyde emission}

The results of formaldehyde emission from the tested panels are shown in Fig. 7. The emission of formaldehyde linearly decreased as charcoal content in the core layer of panels increases, from $2.57 \mathrm{mg} \mathrm{m}^{-2}$ $\mathrm{h}^{-1}$ for panels o to $0.52 \mathrm{mg} \cdot \mathrm{m}^{-2} \mathrm{~h}^{-1}$ for panels 50 , which means a reduction of about $80 \%$ in formaldehyde emission. Extrapolating the linear regression found, formaldehyde emission is expected to completely disappear when the charcoal content in the panels is about $62.6 \%$. Such significant reduction in formaldehyde emission is due to strong ability of charcoal to trap gases in its structure.

A similar effect of formaldehyde content reduction was observed by Kumar et al. (2013) using MDF panels with addition of 0 , $2,5.2$ and $10.4 \%$ wt. of activated charcoal. According to these results, the increasing content of charcoal caused a linear reduction of formaldehyde content from 9.82 $\mathrm{mg} 100^{-1} \mathrm{~g}$ of $6.5 \% \mathrm{MC}$ panels without charcoal to about $7 \mathrm{mg} 100^{-1} \mathrm{~g}$ in panels with $10.4 \%$ wt. of charcoal added, which means a reduction $>28 \%$.

\section{Conclusions}

In this study, the increasing content of charcoal particles in the core layer of particleboards resulted in: (i) a higher densification of face layers; (ii) a significant reduction of the modulus of rupture and a nonsignificant increase of the modulus of elasticity when adding $10 \%$ of charcoal; (iii) a non-significant increase of the internal bond of panels with $10 \%$ of charcoal content, as compared with panels without charcoal, as well as a significant internal bond reduction for $50 \%$ charcoal content panels compared to reference panels; (iv) a significant, almost linear reduction of screw withdrawal resistance; (v) an increase of thickness swelling and water absorption; (vi) a significant, linear reduction of formaldehyde emission. Since charcoal particleboard panels did not meet most of the standard requirements for furniture, their use for interior equipment is recommended for their remarkably lowered formaldehyde emission.

\section{List of abbreviations}

The following abbreviations were used

throughout the manuscript:

- APTES: aminpropyltriethoxysilane;

- BUF: bio-oil urea-formaldehyde;

- EMC: equilibrium moisture content;

- FE: formaldehyde emission;

- IB: internal bond;

- LPL: low pressure laminate;

- MDF: medium density fiberboard;

- MOE: modulus of elasticity;

- MOR: modulus of rupture;

- MPS: methacryloxypropyltrimethoxysila- 
ne;

- MUF: melamine-urea-formaldehyde;

- NCC: nano crystalline cellulose;

- PFO: phenol-formaldehyde oligomers;

- PVC: polyvinyl chloride;

- RH: relative humidity;

- SWR: screw withdrawal resistance;

- TS: thickness swelling;

- UF: urea-formaldehyde;

- UV: ultraviolet;

-WA: water absorption.

\section{Acknowledgements}

Part of this work has been done under statutory research of Department of Technology and Entrepreneurship in Wood Industry, Faculty of Wood Technology, Warsaw University of Life Sciences - SGGW, Poland.

\section{References}

Akgül M, Ayrilmis N, Çamlibel O, Korkut S (2013). Potential utilization of burned wood in manufacture of medium density fiberboard. Journal of Material Cycles and Waste Management 15: 195-201. - doi: 10.1007/s10163-012-0108-3

Chen L, Gao Q, Zhang J, Chen H, Zhang S, Li J (2014). Effects of assembly time on wet shear strength and formaldehyde emission of plywood bonded by urea formaldehyde resin. BioResources 9 (2): 2975-2986. [online]: http:// www.ncsu.edu/bioresources/BioRes_09/BioRes _09_2_2975_b_Chen_GZCZL_Effects_Assembly Time Plywood UF Resin 5202.pdf

Ding W, Li W, Gao Q, Han C, Zhang S, Li J (2013). The effects of sealing treatment and wood species on formaldehyde emission of plywood. BioResources 8 (2): 2568-2582. [online] URL: http://www.ncsu.edu/bioresources/BioRes_08/ BioRes 08 2 2568 Ding_LGHZL Sealing_Treat m_Spec_CH 20 O_Emis_Plywd_3705.pdf

EN310 (1994). Wood-based panels. Determination of modulus of elasticity in bending and of bending strength. CEN, European Committee for Standardization, Brussels, Belgium, pp. 9. [online] URL: http://standards.cen.eu/dyn/www /f?p=CENWEB:105

EN312 (2010). Particleboards - Specifications.
CEN, European Committee for Standardization, Brussels, Belgium, pp. 18. [online] URL: http:// standards.cen.eu/dyn/www/f?p=CENWEB:105

EN317 (1993). Particleboards and fibreboards. Determination of swelling in thickness after immersion in water. CEN, European Committee for Standardization, Brussels, Belgium, pp. 7. [online] URL: http://standards.cen.eu/dyn/www /f?p=CENWEB:105

EN319 (1993). Particleboards and fibreboards. Determination of tensile strength perpendicular to the plane of the board. CEN, European Committee for Standardization, Brussels, Belgium, pp. 8. [online] URL: http://standards. cen.eu/dyn/www/f?p=CENWEB:105

EN320 (2011). Particleboards and fibreboards. Determination of resistance to axial withdrawal of screws. CEN, European Committee for Standardization, Brussels, Belgium, pp. 10. [online] URL: http://standards.cen.eu/dyn/www/f?p=CE NWEB:105

EN717-2 (1999). Wood-based panels. Determination of formaldehyde release. Formaldehyde release by the gas analysis method. CEN, European Committee for Standardization, Brussels, Belgium, pp. 10. [online] URL: http://standards. cen.eu/dyn/www/f?p=CENWEB:105

Huang J, Li C, Li K (2011). A new soy flour-polyepoxide adhesive system for making interior plywood. Holzforschung 66 (4): 427-431. - doi: 10.1515/hf.2011.169

Kumar A, Gupta A, Sharma KV, Nasir M, Khan TA (2013). Influence of activated charcoal as filler on the properties of wood composites. International Journal of Adhesion and Adhesives 46: 34-39. - doi: 10.1016/j.ijadhadh.2013.05.017

Li B, Zhang J, Ren XY, Chang JM, Gou JS (2014). Preparation and characterization of bio-oil modified urea-formaldehyde wood adhesives. BioResources 9 (3): 5125-5133. [online] URL: http://www.ncsu.edu/bioresources/BioRes_09/ BioRes_09_3_5125_Li_ZRCG_Prep_Char_Biooil Mod UF Adhesive 5517.pdf

Li X, Li J, Li J, Gao Q (2015). Effect of sepiolite filler in melamine-urea-formaldehyde resin on the properties of three-ply plywood. BioResources 10 (4): 6624-6634. [online] URL: http:// www.ncsu.edu/bioresources/BioRes_10/BioRes
_10_4_6624_Li_LLG_Effects_Sepiolite\%20Fil Ier_Properties_Melamine_Resin_7673.pdf Luo J, Zhang J, Luo J, Li J, Gao Q (2015). Effect of melamine allocation proportion on chemical structures and properties of melamine-ureaformaldehyde resins. BioResources 10 (2): 32653276. [online] URL: http://www.ncsu.edu/biore sources/BioRes_10/BioRes_10_2_3265_Luo_Eff ect_Melamine_Allocation_Proportion_Chemica I_68 $40 . p d f$

Myers GE, Koutsky JA (1990). Formaldehyde liberation and cure behavior of urea-formaldehyde resins. Holzforschung 44 (2): 117-126. - doi: 10.1515/hfsg.1990.44.2.117

Park CY, Choi CH, Lee JH, Kim S, Park KW, Cho JH (2013). Evaluation of formaldehyde emissions and combustion behaviors of wood-based composites subjected to different surface finishing methods. BioResources 8 (4): 5515-5523. [online] URL: http://www.ncsu.edu/bioresour ces/BioRes_08/BioRes_08_4_5515_Park_CLK_E val_Formaldehyde_Combust_Wood_Composit es_4267.pdf

Shi Y, Chrusciel L, Zoulalian A (2007). Production of charcoal from different wood species. Récents Progrès en Génie des Procédés, Numéro 96/2007, Ed. SFGP, Paris, France, pp. 9. [online] URL: http://hal.archives-ouvertes.fr/ hal-00265340/

Wang W, Zhao Z, Gao Z, Guo M (2012). Waterresistant whey protein based wood adhesive modified by post-treated phenol-formaldehyde oligomers (PFO). BioResources 7 (2): 1972-1983. [online] URL: http://www.ncsu.edu/bioresour ces/BioRes_07/BioRes_07_2_1972_Wang_ZGG_ Water_Resist_Protein_Adhesive_PF_Oligomers 2498.pdf

Zhang H, Zhang J, Song S, Wu G, Pu J (2011). Modified nanocrystalline cellulose from two kinds of modifiers used for improving formaldehyde emission and bonding strength of urea-formaldehyde resin adhesive. BioResources 6 (4): 4430-4438. [online] URL: http://www.ncsu.edu/bioresources/BioRes_06/ BioRes_06_4_4430_Zhang_ZSWP_Mod_NC_Ce Ilulose_CH2O_UF_Adhesive_2052.pdf 